\title{
Mesa Redonda del Coloquio NERUDA CON LA PERSPECTIVA DE 25 AÑOS
}

José Carlos Rovira: Selena Millares hablaba hoy de una "primavera nerudiana», y de hecho estamos en una primavera nerudiana, de momento. Yo recordaba esta tarde un texto de Ernesto Cardenal que se llamaba "La primavera muerta en el tejado" que decía: "Aquel once de septiembre de 1973, recuérdalo... recuérdalo». Hoy estamos en esta primavera a 24 de marzo de 1999, una fecha que tal vez también podrá ser recordada por motivos extra-literarios o no, motivos que, en todo caso, están en la cabeza de todos.

La idea es: Pablo Neruda, ipoeta para el siglo XXI? Cedo pues la palabra al profesor Teodosio Fernández: Pablo Neruda, ¿poeta para el siglo XXI?

Teodosio Fernández: No sé... si son buenos tiempos para la lírica. Yo supongo que Neruda ha cumplido un papel muy importante a lo largo del siglo, y para la poesía hispánica ha sido fundamental la etapa «residenciaria», por ejemplo. Un poeta que descubrió «las estaciones oscuras de la poesía» —que diría algún colombiano-, y que también fue importante para la poesía militante posterior y para la poesía cosmogónica sobre ese mundo recién salido de las aguas. Esas cosas van a permanecer, por lo menos en la historia, y supongo que cada día más, sobre todo los que vamos siendo mayores, apreciaremos más al Neruda último; un Neruda quizás no escéptico, pero sí reflexivo y con capacidad para recuperar el pasado, para ironizar sobre él... Pero no tengo una idea clara de por dónde va a ir el siglo que viene; de todas maneras, yo supongo que todo el mundo leerá Veinte poemas de amor... todos los días.
Paco Tovar: Yo no sé tampoco lo que pueda ocurrir, pero lo cierto es que Pablo Neruda ha sido un poeta muy leído durante todo el siglo XX, y es evidente que se puede leer y se lee de hecho todavía, porque aún hay quien es capaz de relacionarse con una mujer, quien es capaz de relacionarse con las otras personas, quien es consciente de que las cosas continúan siendo difíciles, especialmente en América... No creo que haya cambiado tanto el mundo como para que las modulaciones de Neruda caigan en el cajón más oscuro.

Alain Sicard: Yo tampoco sé mucho, pero, estéticamente, no estoy seguro de que Neruda tenga una gran posteridad en el siglo XXI. Por muchos aspectos lo considero incluso como un poeta del siglo XIX, aunque es un gran poeta de su siglo. Esta definición del poeta, es decir, la mitificación del poeta que protagonizó Neruda no creo que tenga porvenir en el siglo XXI. Pero por lo que sí entiendo que Neruda puede ser un poeta del siglo XXI, es por el mensaje. Lamento que en este coloquio se haya corregido excesivamente una imagen del poeta, de optimismo revolucionario, y que hayamos dejado la imagen de un poeta pesimista. Yo me acuso de haber empleado en alguna oportunidad esta expresión de "pesimismo histórico», pero mi opinión es que pesimismo y optimismo son dos palabras que no sirven para mostrar la actitud de Neruda, el mensaje final de Neruda. Insisto en que es un poeta que nos es muy necesario leer en este fin de siglo donde lo que necesitamos es lucidez, y el Neruda posterior a los años 60 puede dejar una impresión muy favorable. Neruda nos enseña además que la esperanza es una dimensión fundamental de
Neruda con la perspectiva de 25 años

MESA REDONDA 
la Humanidad, y sólo por eso yo creo que es un poeta del siglo que viene.

Hernán Loyola: No tengo mucho que añadir a lo que acaba de decir Alain, que comparto en buena medida. Yo agregaría tan sólo que si tuviera que elegir alguna de las dimensiones del Neruda poeta, diría que es un escritor que tiene algo para cada uno de nosotros. Es decir, Neruda fue un universo, o para decirlo en términos más domésticos, la idea del «poeta alcachofa» que tiene una hojita para cada uno de nosotros. Si uno tiene las obras completas de Neruda, en cualquier estado de ánimo puede dialogar con él en soledad y encontrar una esperanza, si es una pena de tipo sentimental, o simplemente una reflexión. Neruda desarrolla tantas facetas en su vida y en su poesía, que tiene efectivamente un mensaje para cada uno de nosotros y en cada una de las circunstancias. Neruda encarnaba a los seres humanos en todo lo que tenemos de bueno, de malo, de mediocre, de contradictorio, etc.; creo que es uno de los poetas que mejor nos ha representado y habla por todos nosotros. Yo creo que también los hombres y mujeres del siglo XXI tendrán mucho que coger de la poesía de Neruda.

Giuseppe Bellini: A mí me gustaría mucho, dentro de veinte años, verificar esto, pero puesto que no estaré dentro de veinte años, me quedo en las suposiciones. Si nosotros vemos el panorama de la poesía latinoamericana, al menos desde mi punto de vista, ya se han eliminado una infinidad de poetas, y quedan tres, según mi idea: uno es Vallejo, otro es Neruda, y el tercero es Octavio Paz. Estos tres, posiblemente pasen al nuevo siglo, pero seguramente, como decían también otros compañeros, habrá una selección natural dentro de la obra de Neruda. En un periodo se han celebrado determinados títulos; en otro, posiblemente no sean los mismos; pero hay algunos textos como, pongamos, Estravagario, que según mi parecer quedarán. Y ¿cuál es el fundamento de la esperanza o de la certeza de que quedará en el siglo XXI? Es como yo cito siempre en el caso de Leopardi: Leopardi es viejo y sin embargo todo el mundo lo siente como poeta; ¿por qué?: porque encarna una gran parte de las inquietudes del hombre que a través del tiempo son las mismas, yo creo. $\mathrm{Y}$ los grandes poetas no hacen más que interpretarlas; son las suyas y son el espejo de los problemas del individuo en general. En este sentido, además hay esta musicalidad del ritmo, etcétera, a veces digo una prosa nerudiana: «Cuando remotamente regreso». Es suficiente este comienzo para decir que es una prosa extraordinaria, porque suscita una infinidad de cosas dentro de uno cuando la lee. En esta capacidad de suscitar un sinfín de sensaciones a partir de pocas palabras o pocos versos, seguramente Neruda y Vallejo quedarán en el siglo XXI. Si no es así, cuando vengan ustedes conmigo ya me lo dirán.

EnRIQUe Robertson: Yo soy el menos indicado para opinar. No puedo hacer un estudio prospectivo, todo lo mío es retrospectivo como ustedes vieron, es decimonónico, todo tenía que ver con la Inglaterra victoriana y con papeles viejísimos...; de tal manera que paso la palabra a los sabios.

Selena Millares: Seguro que yo soy la que menos tiene que decir en esta mesa en la que estoy rodeada de sabios. Al hilo de todo lo que se ha dicho y de todo lo que hemos sentido en estos días quería hacer dos comentarios nada más. Uno, que si todavía nos sigue haciendo vibrar tanto la poesía de Neruda y la leemos y nos apasiona, pues seguro que es por algo. Y al respecto de las palabras que iniciaban este coloquio con el sabio escepticismo de Teodosio Fernández de que son «malos tiempos para la lírica», yo disiento y creo que a lo largo de los tiempos siempre hacen falta poetas y esas grandes figuras en las que identificarnos y leernos a nosotros mismos; eso ha existido desde los orígenes de la humanidad y eso no puede perderse, es decir, que sí soy absolutamente optimista, optimista militante, en esto. Lo otro que quería comentar es que lo que sí puede hacerse necesario con los nuevos tiempos es una lectura "omnívora», desprejuiciada, de Neruda que prescindiera de todas esas mutilaciones y carnicerías que se le han hecho a lo largo de este siglo, según los intereses de cada momento.

José Carlos Rovira: Yo como estoy de moderador no tengo que opinar. Además la pregunta era para comenzar a hablar y ahora ya no voy a hacer un interrogatorio sino que voy a lanzar dos o tres temas para que los 
conteste quien quiera, antes de dar la palabra a todos los presentes para que pregunten. La primera cuestión es que Neruda es un poeta que ha tenido una determinación biográfica siempre a la hora de la lectura, es decir, que siempre ha tenido una contraseña biográfica detrás, que él mismo ha establecido y ha creado. ¿Es positiva en un poeta esa determinación biográfica y que el poeta siempre crea? Pregunto sobre si esa lectura condicionada por la biografía que él mismo determina - Confieso que be vivido o Memorial de Isla Negra ofrecen claves para la lectura de toda su obra- es, desde una perspectiva crítica que todos conocemos (estoy pensando en las deconstrucciones de Neruda que algunas me han parecido espantosas), la mejor forma de entrar a su obra.

Teodosio Fernández: Yo creo que es fundamental. Menos que otros, pero yo también padecí ese sarampión y pienso que con cualquier escritor lo que tenemos que hacer para empezar es saber qué dice, qué quería decir. En el caso de Neruda su clave biográfica, su biografía, es la biografía de los tiempos que nos tocó vivir. Entonces, supongo que si Neruda es un poeta excepcionalmente rico y que puede comunicar a mucha gente es porque interpretó y sintió muchos momentos y muchas opciones de la historia de este siglo. Ignorar eso es, de entrada, no saber qué dice y si no sabemos qué dice pues no creo que tenga mucho interés... Tengo la impresión de que los que explicamos literatura tenemos la obligación de reconstruir el significado y no de leer como nos dé la gana. Es decir, no vale cualquier lectura, siempre hay unas mejores y otras peores; nuestro deber es dar con la mejor posible. Desde ese punto de vista, la clave biográfica, la clave histórica, es absolutamente necesaria.

Paco Tovar: A mí me gustaría decir que siempre me he planteado (y supongo que eso también es muy sentimental, copiando al profesor Bellini en ese sentido) que cuando uno habla con alguien de una forma normal es evidente que no se puede prescindir de la persona que hay detrás de quien habla. Por lo tanto, a mí me interesa una persona en la medida en que podemos establecer un lazo en común, que puede ser un lazo físico o puede ser un lazo a través de las palabras. Con los poetas y los escritores en general pasa lo mismo: uno elige a sus amigos y a sus enemigos.

AlAin SICARD: A propósito de la autobiografía, quisiera mencionar un aspecto, algo que todavía es un campo virgen para los estudios nerudianos, que es el inconsciente del poeta. En efecto, todos esos rostros de Neruda, ese fondo autobiográfico que tiene la poesía de Neruda, se podría entender como una estratagema o un dispositivo de disimulación de algo más profundo. Hay un poema de Neruda que yo encuentro misterioso; lo sé de memoria: «Lo que no me pasó fue tan súbito que ahí me quedé para siempre». Yo creo que Neruda como todos los poetas, todos los artistas, tenía un inconsciente, pero ese inconsciente fue cuidadosamente disimulado, y cuidadosamente ignorado también por la crítica nerudiana. Ahora, no sé por dónde habría que buscar para investigar sobre esto; bueno, yo lo intenté un poco en mis libros a partir del tema de los dos nacimientos: Neruda nació en el Parral y tuvo otro nacimiento luego en la frontera. Hay un poema de Neruda que se llama "Nacimiento" (Memorial de Isla Negra) que me parece interesante desde este punto de vista, es un poema sobre la madre y sobre este primer nacimiento que a mí me hizo pensar. También vemos en otros poemas de Memorial... el descubrimiento del sexo por el poeta: él cuenta cómo con las Pacheco, sus pequeñas vecinas en casa, experimentó sus primeras emociones sexuales. Yo creo que allí hay algo que investigar y que sería muy interesante.

HeRnán Loyola: Esto de la proyección biográfica de Neruda sobre su propia poesía es un problema con el cual me enfrenté desde siempre. A pesar de ciertas críticas, me vi obligado a pensar cuál era la relación de la poesía de Neruda con la experiencia del poeta. Yo diría sólo dos cosas: una, la biografía del poeta, el conocer la experiencia biográfica, en el caso de Neruda me parece de gran utilidad como clave de desciframiento, porque la poesía de Neruda, sobre todo la primera, la de Residencia en la tierra, pero también su poesía tardía, es un constante codificar, un constante cifrar la propia experiencia. Pero es muy importante no confundir dos aspectos, que es más o menos lo que se decía aquí a propósito de la narración de la novela y el narrador pro-
Neruda con la perspectiva de 25 años

MESA REDONDA 
tagonista: una cosa es la condición autorial y otra cosa es el personaje; Neruda en su poesía habla de sí mismo y se refiere a sí mismo, incluso se nombra a sí mismo aunque tardíamente; pero una cosa es el personaje que él inventa y otra, el ciudadano Pablo Neruda. El personaje que vive en sus textos es el resultado no de una ficción, sino de una selección que va terminar en una especie de ficción. Pero sobre todo, lo que yo creo definitivo en este sentido es que Neruda cuando habla de sí mismo, lo que hace es decirnos que cada uno de nosotros puede ser un personaje, un protagonista extremadamente interesante, que cada uno de nosotros es interesante si sabemos construirnos como personaje, si tenemos interés en comunicarlo a los demás. Sobre este punto de su poética él insistió muchas veces: él era uno entre otros. Espero que se haya entendido.

Giuseppe Bellini: Espero que se me entienda a mí también. La biografía de un autor puede contemplarse desde varios puntos de vista. A mí me parece que es importante saber quién es este señor, cuál ha sido y cuál es la historia de su vida, pero naturalmente la parte más interesante es ver la biografía escondida, ver quién es a través de su poesía, porque muchas veces puede no corresponder a la biografía material que nosotros conocemos. En este sentido, es evidente que este hombre que dice «soy alegre y otoñabundo", ya presenta dos términos muy interesantes para poder penetrar dentro del personaje. Por esto es interesante Neruda, desde mi punto de vista, porque tiene estas grandes posibilidades de poder buscar y encontrar quién es; quién es y quiénes somos nosotros también, porque a la vez que lo descubrimos nos descubrimos a nosotros mismos.

TEOdosio FERnÁndeZ: Quisiera puntualizar algo de lo que había dicho antes. Yo creo que con la biografía y con la historia también hay que ser cauto: creer que Whitman era un señor que andaba con todas las muchedumbres de América y por toda la geografía americana es equivocarse porque no había salido de su casa. La biografía, en un sentido estricto, las experiencias de la persona que escribe, pueden ayudar a explicar el porqué de lo que dice y del personaje, de la voz o de las muchas voces que construye.
Giuseppe Bellini: Quiero añadir una cosa por lo que decía Teodosio Fernández. El ejemplo lo tenemos en la literatura italiana: Gabrielle D'Annunzio. Sabemos todos sobre su biografía, pero no nos interesa absolutamente -y su obra tampoco nos interesa-, ya pasó, no nos dice nada, no tiene dimensión...; bueno es una obra extraordinaria desde el punto de vista lingüístico, etcétera, inventivo...

ENRIQUe Robertson: Yo lo que puedo decir es que habiendo sido un niño del sur de Chile, de la frontera, y habiendo recorrido las mismas calles, visitado los mismos lugares que Neruda, tenía la sensación, a lo mejor exagera$\mathrm{da}$, de identificarme con ese muchacho de dieciséis años que salió de Temuco con rumbo al mundo. Pero, por supuesto, ya lo dije, no soy filólogo ni estudioso, soy lector de Neruda, y sus poemas y sus autorreferencias a veces me dicen: «a lo mejor eres tú mismo ahí»; me encuentro en sus cosas, si no, no me interesaría. Y por eso creo que tiene toda la razón el profesor Bellini cuando dice que ésta es una biografía interesante. La mía no, no es tanto, mejor dicho, es absolutamente interesante, pero cuando lo leo reconozco esos muchachos del liceo de Temuco, esa gente de allí, del sur, y las vivencias de las lluvias, de los bosques, del mar de Puerto Saavedra, etcétera, etcétera. Es una cosa muy personal, por eso la vivo más de cerca, no sé si será verdad, pero así lo siento.

Selena Millares: Yo solamente quería anotar que siempre es peligroso caer en esa falacia del biografismo, de confundir el texto literario o el poema que estamos leyendo con la persona. Creo que es una ambivalencia que esta ahí, y hay un texto de Borges muy bonito donde dice que el poeta o el escritor se pasa la vida dibujando una geografía y de pronto, al final, descubre que ese dibujo es su propia imagen, y sin duda esa imagen es él, pero también no es él. También se mencionaba ahora al poeta Whitman, y me interesa la mención porque era uno de esos acreedores que nombraba Neruda; y Whitman tiene ese poema, que por cierto también traduce Borges, el "Canto a mí mismo", pero el "Canto a mí mismo", y lo digo a colación de Neruda, no esuna autoexaltación de Walt Whitman como hombre, sino que él se ficcionaliza con el hombre en general y se identifica con él. 
Entonces hay todo ese juego y hay que entenderlo. Y ahí está el metal humano vertido sobre la poesía, y seguramente nos pondría en muchísimos problemas para entenderla y sentirla el estar buscando por detrás y tratando de identificar al poeta. Por último, quiero decir que Neruda, sin duda, era un animal poético y tenía ese modo del camaleón de ir tranformándose y ser siempre distinto y siempre el mismo; y el era Neftalí y era Pablo Neruda y era todos esos personajes que pululan por sus versos en determinadas ocasiones. $\mathrm{Y}$ todos esos rostros, como en un poliedro, no son traiciones, autotraiciones que uno tenga que cuestionar, son parte de la contradictoria unidad que puede tener cualquier ser humano, y ahí está su grandeza.

PACO Tovar: No hay que llamarse a equívocos con esa pregunta inicial, la biografía de Neruda, etcétera, etcétera. Todo eso es cierto pero en la medida en que se entiende el interesar la biografía en función, naturalmente, de ese diálogo, de esa conversación, de ese estar continuo con el libro o con Neruda en la mano.

José Carlos Rovira: Vamos ahora a dar la palabra al público.

UN MIEMBRO DEL PÚBLICO: quiero opinar sobre la cuestión que se está planteando, si es Neruda un poeta para el siglo XXI. Yo creo que es del XX, y recuerdo un libro, definitivo a mi parecer, de Roger Woolf — que, por cierto, vivió en Alicante- Días perdidos en los transportes públicos, y veo que hay toda una poética que ya está en Pablo Neruda y que recupera la poesía sucia. Y otro libro perdido, en el 79, Javier Marín Ceballos publica Bufes vida mía, que es la poesía del humor de Neruda y de Nicanor Parra, la poesía coloquial. Y bueno, termino recordando ese final de Neruda sobre el libro: «cuando te cierro, abro la vida». Y hay que leer a Neruda para abrir la vida. Entonces, ¿poeta del XXI? Desde luego que sí.

Otro MIEMbro Del público: Quisiera saber cuánto se ha traducido a Neruda.

José Carlos Rovira: El profesor Bellini podría hablarnos sobre las traducciones en Italia.
Gruseppe Bellini: En Italia lo hemos traducido casi todo, menos La Barcarola y... nada más, todo lo demás lo hemos traducido, hasta la prosa. Ahora se vuelve a editar todo: han salido de nuevo "las Residencias", Memorial de Isla Negra, Estravagario, una antología de poesía de amor, salen las obras póstumas, etc., etc.

José Carlos Rovira: Alain Sicard, que también le ha traducido, podría informarnos de las traducciones francesas.

Alain Sicard: Hablar de las traducciones de la poesía en Francia o de la literatura extranjera es hablar también, desgraciadamente, de la impermeabilidad de este país a lo extranjero. Un poeta del tamaño de Neruda tuvo que esperar el premio Nobel para tener más de dos libros, porque solamente había dos libros traducidos y de un modo espantoso, uno era Residencia...: cada poema en la traducción tiene tres, cuatro, cinco errores; y nadie sabe por qué no está el texto español al lado. Los franceses creen que esto es lo que dice Neruda, pero muchas veces tiene poco que ver. Así que la traducción es muy tardía. Yo creo que, por motivos ideológicos, se trató de tapar un poco esta figura, también porque la poesía sin pureza es una poesía que va a contrapelo de nuestra tradición francesa o de lo que pensamos que es nuestra tradición, porque es una tradición bastante joven, la que se remonta a Mallarmé y la poesía pura. La poesía pura sigue siendo la base fundamental de la cultura literaria en Francia. Desgraciadamente hay grandes escritores, inmensos escritores franceses, como Rabelais que a mi modo de ver es un escritor infinito, del tamaño tal vez de un Shakespeare, y que no entra casi en nuestra cultura. Así que tenemos una tradición de la cultura exquisita los franceses, las cosas pequeñas, y esta poesía torrencial sin pureza yo creo que no entraba en los esquemas de la crítica francesa, de muchos lectores franceses, probablemente tampoco, de las editoriales por motivos ideológicos... Y eso explica que solamente cuando Neruda recibe el premio Nobel empieza a ser conocido en sitios no intelectuales, con un público ancho y diverso.

PAco Tovar: Antes se ha contado una anécdota muy curiosa, y vuelvo a lo de la bio-
Neruda con la perspectiva de 25 años

MESA REDONDA 
grafía, que creo que es significativa. Se trata de ese sistema para aproximarse a las damas que tenía Neruda, y que más o menos decía: elige bien a la mujer que te interese, hazte el encontradizo con ella y dile "lo sé todo», y verás cómo vuelve. Lo que nos está diciendo ese sistema de seducción, traducido al ámbito del lector, es que el poeta se ha fijado muy bien en cada uno de nosotros, se nos ha cruzado en el camino $y$, entonces, nos ha dicho «lo sé todo». Naturalmente no ha quedado más remedio que volver a sus libros a pregutarle «qué sabes».

OTRO MIEMBRO DEL PÚBLICO: Suele decirse que Neruda descubre América en México. ¿Es una cuestión de madurez de Neruda o es que México le descubre algo que no tiene Chile?

Teodosio Fernández: Creo que cuando Neruda llega a México, el país, con la colaboración de los franceses, está creando una imagen que se vendió a toda Hispanoamérica y para todo Occidente, y de la que todos se aprovecharon. Quizás hay cosas antes de que llegue Neruda que ya son muy importantes, como las relaciones que Neruda tuvo con el surrealismo y la vinculación de éste con la posibilidad trotskista; $y$ esto tiene que ver con que después gente como Carpentier o el propio Neruda negasen la afiliación de lo que en México descubrieron. Creo que todo comienza, recordando lo que había por México unos años antes, en los años 20 , cuando Ribera empieza a decir que lo auténticamente mexicano es el indio y que la revolución es la esencia de la identidad mexicana; y a partir de ahí empieza a intervenir gente como Robert Desnos, que habla de la pintura mexicana y de Ribera defendiendo a pistoletazos sus murales...; y se va creando la imagen de un México violento, atractivo, que después alguien como Antonin Artaud cultivó cuando quiso hacer «teatro de la crueldad» en obras como $\mathrm{La}$ conquista de México. Los mexicanos no tenían ni idea de que México era así, y de las virtudes de las culturas primitivas, tampoco. Todo eso va calando y cuando Bretón llega en el 38 a México —aleccionado quizás por Artaudapuesta por el México mágico y mítico. Y otro momento importante es la vuelta de Reyes, que empieza hablar de los mitos de la conquista y de una América nacida de la ima- ginación de Occidente. Y entonces el padre Garibay saca a relucir textos de la literatura náhuatl. Hay muchas cosas, por tanto, que crean un ambiente y ponen de moda las virtudes de lo telúrico, de las fuerzas de la naturaleza. Yo tengo la impresión de que en ese momento todos descubrieron América. Todas esas referencias están en el Canto General... Lo que quiero decir es que Neruda, como cualquiera y sin perjuicio de su regionalidad, cuando necesita construir una visión del mundo, la construye con los medios que su época le proporciona, y jamás ha ocurrido otra cosa: nadie puede no ser de su época.

Alain SiCARD: Yo quería decir que si leen la obra de Neruda, el indio ocupa muy poco lugar en la obra de Neruda. Habla del indio en Alturas de Macchu Picchu, pero no de un modo indigenista, y luego le dedica al indio un poema en el Canto General y lo trata un poco en La Barcarola, pero no es su tema. La América de Neruda no es una América indigenista, no creo que haya esta preocupación del indio en la obra de Neruda. Por eso yo estoy de acuerdo en que ciertos latinoamericanos han descubierto América o su cultura indígena desde Europa: es el caso de Asturias, tal vez de Carpentier o de otros que no recuerdo, pero en el caso de Neruda no hay el tópico de una América india.

HeRnán Loyola: Hay un problema que visto desde Europa parece difícil de entender. Cuando un europeo piensa en sus orígenes, piensa en los romanos o que vive en una ciudad en la que camina por calles que tienen un milenio y algo más; esto para nosotros es impensable, porque nosotros nacimos a la historia y en eso estoy muy de acuerdo con lo que dice Alain Sicard. Pero se trata de un problema de autoconciencia, él mismo me decía antes de empezar que Neruda conoció América en España, pero lo que Neruda quiso decir es que el tener conciencia de ser americano fue en él un proceso, como lo ha sido a partir de los años veinte para la cultura hispanoamericana en su conjunto. En el caso concreto de Neruda, hay un poema escrito en España que aparentemente no tiene que ver con esto, "Enfermedades en mi casa" sobre la enfermedad de su única hija Malva Marina, pero es en ese poema donde para mí por primera vez Neruda toma, desde España, con- 
ciencia de su ser americano en un sentido casi irracional mítico, en una plegaria a los dioses del paisaje de su infancia en Temuco («Ayudadme hojas del Sur, lluvia...»). Es un paisaje que estaba ya presente en libros anteriores, pero aquí se dirige Neruda por primera vez a su América.

Teodosio Fernández: Yo creo que tampoco se trataba de hablar del indio, se trataba de ver una América donde los personajes americanos son un producto muy ligado a la tierra, y la injerencia de los extranjeros es como una violación de la naturaleza. La idea de la América violada.

Giuseppe Bellint: Habría que profundizar en la influencia que tiene la estancia del poeta en París en el descubrimiento de América. No hay que olvidar que Francia tiene una historia con México, y se entiende que México tenga una presencia importante en Francia. Si hubieran ido a Italia, habrían descubierto posiblemente Argentina. Creo que Neruda hace lo que he hecho yo con la literatura hispanoamericana: buscar en las raíces indígenas para darle a la literatura hispanoamericana una dignidad mayor. $Y$ pienso que Neruda hacía esto no en función del indígena sino como fundamento de Civilización.
PACO TOVAR: Una referencia que puede resultar interesante es el hecho de que en ese descubrimiento de América del que estamos hablando no sólo cuenta el periodo de descubrimiento y colonia, sino un segundo periodo de descubrimiento del indio a finales del siglo XVIII, en el que se utilizan las crónicas de la conquista de México.

Teodosio Fernández: Yo con lo que no estoy de acuerdo es con la idea de que América se descubre ahora, en los años 40. Se forja una imagen de América de acuerdo con las expectativas del momento. Lo que dice Paco Tovar es verdad: los europeos fundaron la imagen, en la disputa del Nuevo Mundo, de un mundo recién nacido, pero entonces los hispanoamericanos la conjuraron desde una perspectiva racionalista, mientras que la América que se construyó en este siglo es la América que todos los que creían en la decadencia de Occidente esperaban encontrar.

José Carlos Rovira: Para concluir, quiero agradecer su presencia a todos los ponentes $\mathrm{y}$ asistentes, $\mathrm{y}$ terminaré con una frase nerudiana de Confieso que be vivido: «Caramba, la primavera es inevitable». 